\title{
Structural and functional characterization of thermostable biocatalysts for the synthesis of 6-aminopurine nucleoside- 5'-monophospate analogues
}

Jon Del Arcoa, Elena Péreza, Hisashi Naitowb, Yoshinori Matsuurab, Naoki Kunishimab, Jesús Fernández-Lucas

\section{Abstract}

The present work describes the functional and structural characterization of adenine phosphoribosyltransferase 2 from Thermus thermophilus HB8 (TtAPRT2). The combination of structural and substrate specificity data provided valuable information for immobilization studies. Dimeric TtAPRT2 was immobilized onto glutaraldehydeactivated MagReSyn ${ }^{\circledR}$ Amine magnetic iron oxide porous microparticles by two different strategies: a) an enzyme immobilization at $\mathrm{pH} 8.5$ to encourage the immobilization process by N-termini (MTtAPRT2A, MTtAPRT2B, MTtAPRT2C) or b) an enzyme immobilization at $\mathrm{pH} 10.0$ to encourage the immobilization process through surface exposed lysine residues (MTtAPRT2D, MTtAPRT2E, MTtAPRT2F). According to catalyst load experiments, MTtAPRT2B (activity: $480 \mathrm{IU}$ g-1 biocatalyst, activity recovery: 52\%) and MTtAPRT2F (activity: 507 IU g-1 biocatalyst, activity recovery: 44\%) were chosen as optimal derivatives. The biochemical characterization studies demonstrated that immobilization process improved the thermostability of TtAPRT2. Moreover, the potential reusability of MTtAPRT2B and MTtAPRT2F was also tested. Finally, MTtAPRT2F was employed in the synthesis of nucleoside-5'-monophosphate analogues.

Keywords:

Thermophiles, Biocatalysis, Enzyme Immobilization, Protein crystallography 